\title{
10 NĂM ĐẠI HỌC TƯ THỤC VIẸTT NAM: Ai sở hữu, bao nhiêu tiền và liệu còn đất cho tay chơi mới?
}

\author{
Đàm Quang Minh, Hoàng Anh Đức, Phạm Hiệp
}

Sự công nhận chính thí̛c "chủ sở hữu tư nhân" vào năm 2005 không chỉ đơn thuần là mốc đánh dấu sự khai sinh mô hình đại học tu thuc (ĐH TT) mà còn tạo ra nhiều động lực để các nhà đầu tu tu nhân tham gia vào thị truờng vốn chỉ dành cho khu vực công này. Trong vòng hơn 10 năm qua, các truờng $Đ H$ TT đã có nhũng sự phân hoá dễ nhận thấy về cả quy mô lẫn định hướng hoạt động, mà nguồn căn của những khác biệt đó đều nằm ở mô hình quản trị đại học.

\section{Mô hình quản trị Đại học Tư thục Việt Nam}

Khoảng 30 năm trước, các trường đại học dân lập (ĐH DL) đầu tiên ra đời, hoạt động như những phiên bản không hoàn chỉnh của đại học công lập cùng thời: được vận hành bởi là các nhà giáo, quan chức về hưu cùng lối quản trị truyền thống, nhưng lại thiếu nguồn lực do không được hỗ trợ từ ngân sách nhà nước. Thêm vào đó, trong suốt một giai đoạn dài từ đầu những năm 1990 đển giữa những năm 2000, sự sở hữu tư nhân không được thừa nhận, khiến cho các trường $Đ H$ ngoài công lập $(\mathrm{NCL})$ càng không có động lực để cải tổ từ chính bên trong.

Quyết định 14/2005/QĐ-TTg, thực tế đã khai sinh mô hình đại học tư thục (ĐH TT), chính thức công nhận "chủ sở hữu tư nhân" đối với ĐH NCL, điều trước đó vốn không được chấp nhận ở mô hình dân lập.

Việc điều chỉnh mô hình sở hữu không chỉ cởi trói cho các ĐH TT trong việc kêu gọi thêm nguồn đầu tư, mà còn ảnh hưởng rất lớn đến việc cải tổ, vận hành và xây dựng chiến lược dài hạn của trường $\mathrm{OH} \mathrm{TT}$ (hay quản trị đại học). Quản trị đại học chính là một đòn bẩy hữu hiệu để cải thiện chất lượng trong mọi phương diện của giáo dục đại học, là tâm điểm của thành công hoặc thất bại của bất kì trường đại học đương thời nào ${ }^{1}$.

Trong hơn 10 năm qua, cùng với sự tang trưởng về số lượng, chúng ta đã chứng kiến sự phong phú và đa dạng về mô hình quản trị ĐH TT khác nhau. Dựa trên hai thuộc tính của quá trình ra quyết định điều hành (tính mở và tính nhất quán), chúng tôi chia các trường ĐH TT Việt Nam theo 4 mô hình quản trị:

\footnotetext{
${ }^{1}$ Hénard, F., \& Mitterle, A. (2010). Governance and quality guidelines in Higher Education. A review of governance arrangements and quality assurance. Berlim: OECD.
} 


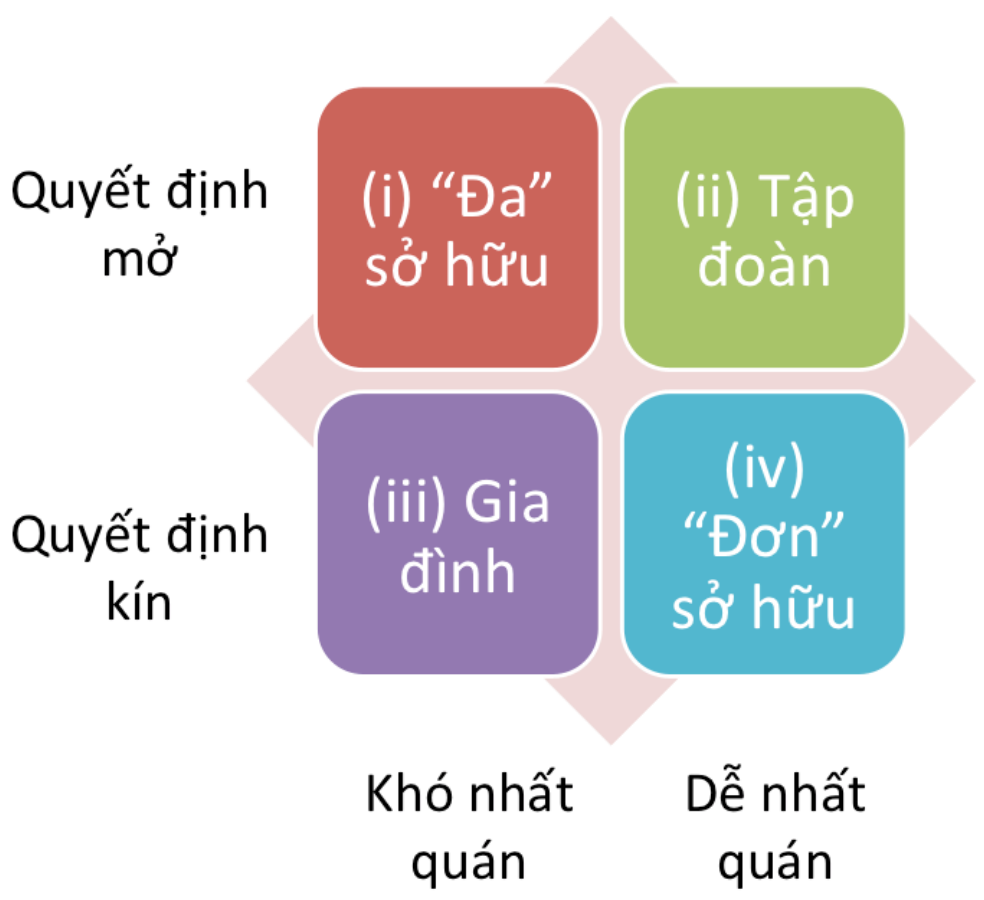

(i) Mô hình gia đình: Các cổ đông chính đều là thành viên trong cùng một gia đình, dòng họ, tham gia hoạch định và điều hành trực tiếp các hoạt động của trường (ĐH Duy Tân, DL Hải Phòng...)

(ii) Mô hình hình "đơn" sở hữu (cá nhân): HĐQT có xuất hiện nhiều nhóm cổ đông khác nhau, nhưng thực tế có một cổ đông đóng vai trò áp đảo và chi phối toàn bộ hoạt động (ĐH Thăng Long, Thành Đô, Đông Á...)

(iii) Mo hinh tập đoàn: Được sở hữu toàn bộ hoặc chi phối bởi một hoặc nhiều tập đoàn kinh tế, hưởng lợi từ mô hình quản trị chuyên nghiệp, các lợi thế về nguồn vốn, cơ sở vật chất, đầu ra cho sinh viên... (ĐH Nguyễn Tất Thành, FPT, Quốc tế Sài Gòn...).

(iv) Mo hìn "đa" sở hũu: Hoạt động của trường được hoạch định và vận hành bởi sự thống nhất của nhiều nhóm cổ đông khác nhau (ĐH Tài chính Marketing, Kinh doanh và Công nghệ, Thành Tây...).

Xét theo tính mở của quá trình ra quyết định, ta có thể thấy rõ sự khác biệt giữa lối quản trị tán quyền và tập quyền. Với phương thức tán quyền, (i) mô hình "đa" sở hữu và (ii) mô hình tập đoàn buộc các quyết định về quản trị, vận hành phải được thảo luận mở trong HĐQT, đòi hỏi chất lượng vận hành ngày càng phải nâng cao, đảm bảo quyền lợi cho nhiều đối tượng cổ đông. Trong khi đó, (iii) mô hình gia đình và (iv) mô hình "đơn" sở hữu lại tập trung quyền lực, các quyết sách lớn thường được thảo luận trong một phạm vi hẹp hơn, giới hạn giữa các thành viên trong một gia đình, dòng họ, hoặc được quyêt định bởi một cá nhân duy nhất. 


\section{Quy mô tài chính}

Các ĐHTT ở Việt Nam gần như không nhận ngân sách nhà nước; nguồn thu chủ yếu đến từ học phí sinh viên; vì vậy, muốn phát triển thì trước tiên các ĐH TT phải có nền tảng tài chính vững vàng trước tiên.

Trên cơ sở đó, vì dữ liệu thực về doanh thu các trường ĐH tư thục Việt Nam còn khan hiếm nên chúng tôi đề xuất thay thế bằng chỉ số "Quy mô tài chính" (bằng tích của quy mô đào tạo và học phí trung bình cho cả khoá học) như một tiêu chí bước đầu để phản ánh mức độ thành công của các mô hình quản trị đại học, bất kể thâm niên, phân khúc và chiến lược hoạt động. Dựa trên chỉ số "Quy mô tài chính", các trường ĐHTT Việt Nam được chia thành 4 nhóm từ $\mathrm{Q} 1$ đến $\mathrm{Q} 4$, với quy mô tài chính lần lượt ở các mức: (1) trên 500 tỷ; (2) 200 400 tỷ; (3) 50 200 tỷ; và (4) dưới 50 tỷ.

Hình 2. Tương quan Quy mô Tài chính (đơn vị Tỷ đồng), Quy mô Sinh viên theo tùng phân khúc

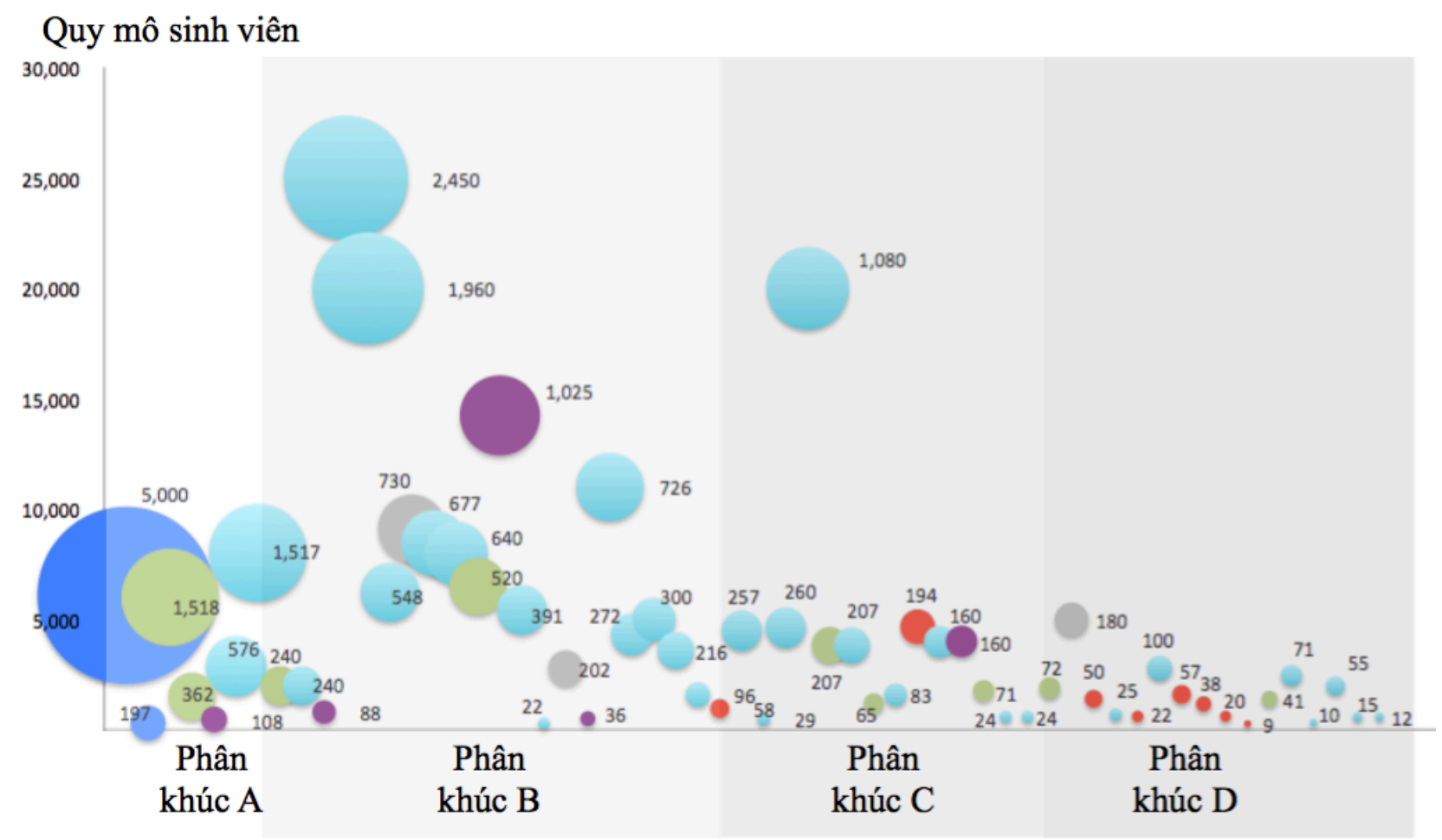

Tương quan Quy mô Tài chính, Quy mô Sinh viên theo từng phân khúc

Quốc tế $\square$ Tập đoàn $\square$ Đa sở hữu $\square$ Gia đình $\square$ Đơn sở hữu $\square$ Chưa xác định

Kết quả tính toán thể hiện rõ hai xu hướng phát triển: (1) các trường chú trọng chất lượng; và (2) các trường chú trọng quy mô. Với xu hướng tập trung phát triển chất lượng đào tạo, các trường có học phí ở phân khúc $\mathrm{A}$ thường có quy mô không quá 10,000 sinh viên và đa phần có quy mô tài chính ở nhóm Q1. Ngoài ĐH Quốc tế Sài gòn đứng đầu trong Q2, với khoảng cách để vươn lên Q1 không quá xa, thì có ĐH Anh Quốc (BUV) và ĐH Tân Tạo nằm trong $\mathrm{Q} 3$. Trong khi $\mathrm{BUV}$ mới thành lập và quy mô tài chính ở mấp mé $\mathrm{Q} 2$, thì $\mathrm{ĐH}$ 
Tân Tạo có thể được coi là một ví dụ điển hình cho việc định vị sai phân khúc và nhiều sai lầm về quản trị: mức học phí quá cao so với chất lượng đào tạo chưa thực sự nổi trội. Đối với xu phát triển quy mô, các trường với quy mô $15 \sim 20,000$ sinh viên thường định vị học phí ở phân khúc $\mathrm{B}$ với chất lượng vừa phải, thành công điển hình là $\mathrm{ÐH}$ Công nghệ Tp Hồ Chí Minh (HUTECH) và ĐH Nguyễn Tất Thành.

Chỉ số "Quy mô tài chính" cũng minh chứng rõ ràng cho dự báo của chúng tôi từ năm $2014^{2}$ về sự sụp đổ các trường phân khúc $\mathrm{D}$ với chất lượng thấp và học phí thấp. Quy mô đào tạo của các trường này không quá 1,000 sinh viên, nằm hoàn toàn từ nửa cuối $\mathrm{Q} 3$ và chiếm tỉ lệ áp đảo trong $\mathrm{Q} 4$. Bên cạnh đó, $\mathrm{Q} 4$ cũng chứng kiến sự góp mặt của một số trường phân khúc $\mathrm{B}, \mathrm{C}$ đang lúng túng trong việc định vị, có khả năng phải đóng cửa hoặc được mua lại bởi các nhà đầu tư chuyên nghiệp.

Bên cạnh đó, ta có thể dễ dàng nhận thấy sự phân hoá về quy mô tài chính của các trường theo mô hình quản trị. Có tới 11/14 trường ở Q1 (quy mô trên 500 tỷ) được quản lý theo mô hình tán quyền. Toàn bộ 11 trường trong Q2 (quy mô từ 200 400 tỷ) được quản trị bởi mô hình đa sở hữu, hoặc có sự chi phối áp đảo bởi một tập đoàn. Trái lại, các trường được quản trị bởi mô hình gia đình hay sở hữu đơn cá nhân rất khó có thể leo lên được $\mathrm{Q} 1$ và Q2, tập trung phần lớn ở $\mathrm{Q} 4$ (quy mô dưới 40 tỷ) và rải rác ở Q3 (quy mô từ 50 đến dưới 200 tỷ).

Trong số 59 trường được thống kê, có 13 trường theo mô hình tập quyền (sở hữu gia đình, hoặc đơn sở hữu), chiếm $22 \%$. Tuy nhiên trong số 13 trường này, chỉ có 1 trường duy nhất trong nhóm Q1, Q2. Kết quả phân phối này phần nào thể hiện rõ khả năng thành công của mô hình quản trị đa sở hữu, và sự hỗ trợ từ các tập đoàn sở hữu với lợi thế của mô hình quản trị hiện đại.

\section{Thành công nhờ khác biệt}

ĐH FPT được chi phối bởi một cổ đông duy nhất - tập đoàn FPT, gắn liền sự phát triển của trường với ICT, thế mạnh của tập đoàn FPT, là đại học đầu tiên được kiểm định 3 sao của QS Star.

Không có lợi thế về mặt quản trị, ĐH Duy Tân ghi danh mình bởi những nỗ lực quốc tế hoá toàn diện, đặc biệt chú trọng phát triển nghiên cứu khoa học. Hiện tại, trường xếp hạng 13/299 trường đại học Việt Nam về kết quả công bố ISI, cũng như là cơ sở giáo dục đại học đầu tiên trở thành thành viên chính thức của sáng kiến CDIO về phát triển chương trình đào tạo.

ĐH DL Lạc Hồng gắn chặt tên tuổi của mình với cuộc thi Robocon với 7 lần vô địch quốc gia, và 2 lần vô địch Châu Á - Thái Bình Dương.

\footnotetext{
${ }^{2}$ Xem: https://hocthenao.vn/2014/09/12/giao-duc-ngoai-cong-lap-o-viet-namdam-quang-minh-pham-thi-ly/
} 
ĐH Hoa Sen cũng rất thành công trong việc định vị sinh viên của mình với "đặc sản" chương trình giáo dục tổng quát giúp sinh viên ra trường khả năng ngoại ngữ tốt, tính tự lập cao, kỹ năng đa dạng và khả năng hội nhập quốc tế.

\section{Dư địa và xu hướng phát triển}

Cũng như nhiều nước trên thế giới, 30 năm qua tại Việt Nam chứng kiến sự gia tăng sức ép ngày càng lớn từ phía người dân về cơ hội đi học đại học. Điều này dẫn đến một hệ quả tất yếu là nhà nước không còn đủ khả năng bao cấp hoàn toàn giáo dục đại học như trước kia nữa. Đối diện với vấn đề này, các nhà nghiên cứu giáo dục đã chỉ ra 2 hướng giải quyết chính:

- Một là: cho phép đại học công mở thêm nhiều chương trình thu phí hoàn toàn để đáp ứng nhu cầu thị trường; hạn chế hoặc không cho đại học tư phát triển.

- Hai là: nhà nước chỉ tiếp tục bao cấp (toàn phần hoặc một phần lớn) giáo dục đại học công và để cho giáo dục đại học tư phát triển đáp ứng nhu cầu thị trường

Phần lớn các nước trong khu vực Đông Á và Đông Nam Á lựa chọn cách thứ hai. Theo thống kê, Indonesia vào năm 2012 có 2818 đại học tư, chiếm tỷ lệ $97 \%$ số đại học tại nước này; các con số tương ứng với Hàn Quốc (2012), Lào (2012), Malaysia (2012), Philippines (2012), Thái Lan (2012), Trung Quốc (2011) lần lượt là 350 (85\%), 77 (78\%), 491 (96\%), $1636(88 \%), 71(42 \%), 836(31 \%)$. Về số lượng sinh viên, các trường tư tại các nước này cũng chiếm tỷ lệ lớn, như tại Hàn Quốc (2011), $81 \%$ là sinh viên ĐH tư, con số tương ứng tại một số nước có tỷ lệ cao là Indonesia (2011): 62\%, Trung Quốc (2011): 63\%, Philippines (2011): 63\% ....

\section{Bảng 1: Số lượng trường và sinh viên ĐHTT tại Việt Nam và một số nước trong khu} vực trong những năm gần đây

\begin{tabular}{|c|c|c|c|c|}
\hline Nước & $\begin{array}{c}\text { Số lưọ̀ng } \\
\text { trường ĐH } \\
\text { công lập } \\
\text { (2012) }\end{array}$ & $\begin{array}{l}\text { Số lường } \\
\text { trường } \\
\text { ĐHTT } \\
\text { (2012) }\end{array}$ & $\begin{array}{c}\text { \% ĐHTT } \\
\text { trên tổng số } \\
\text { trường ĐH } \\
(2012)\end{array}$ & $\begin{array}{c}\text { \% SV ĐHTT } \\
\text { trên tổng số } \\
\text { sinh viên } \\
(2011)\end{array}$ \\
\hline Campuchia & 34 & 57 & $63 \%$ & $60 \%$ \\
\hline Trung Quốc & $\begin{array}{c}1,887 \\
(2011)\end{array}$ & $\begin{array}{c}836 \\
(2011)\end{array}$ & $\begin{array}{c}31 \% \\
(2011)\end{array}$ & $63 \%$ \\
\hline Indonesia & 83 & 2,818 & $97 \%$ & $62 \%$ \\
\hline Hàn Quốc & 61 & 350 & $85 \%$ & $81 \%$ \\
\hline Lào & 22 & 77 & $78 \%$ & $26 \%$ \\
\hline Malaysia & 20 & 491 & $96 \%$ & $43 \%$ \\
\hline Philippines & 220 & 1,636 & $88 \%$ & $63 \%$ \\
\hline Singapore & 5 & 31 & $86 \%$ & $64 \%$ \\
\hline Thái Lan & 98 & 71 & $42 \%$ & $18 \%$ \\
\hline Việt Nam & $\begin{array}{c}170 \\
(2016) \\
\end{array}$ & $\begin{array}{c}65 \\
(2016) \\
\end{array}$ & $\begin{array}{c}28 \% \\
(2016) \\
\end{array}$ & $\begin{array}{c}14 \% \\
(2016)\end{array}$ \\
\hline
\end{tabular}


Source: tổng hợp từ Chapman \& Chien $(2014)^{3}$ và MOET (2017) ${ }^{4}$

(Trong ngoặc là số năm tương ứng)

Với Việt Nam, dường như trong cả một thời gian dài, chúng ta đã lưỡng lự giữa cả 2 cách trên và cuối cùng là chọn cả 2 cách nhưng không cách nào thực sự quyết liệt. Kết quả là tại thời điểm hiện nay, trong khi hệ tại chức, từ xa, hệ đóng tiền tại các trường công không thực sự phát triển; và khu vực $Đ H ~ N C L$, sau 30 năm xuất hiện với danh nghĩa $\mathrm{ĐH}$ DL và 12 năm xuất hiện với danh nghĩa ĐHTT, cũng mới chỉ đóng góp số lượng rất khiêm tốn: $28 \%$ theo tổng số trường $\mathrm{ĐH}$ và $14 \%$ theo tổng số $\mathrm{SV}$ vào năm 2016 . Nói cách khác, từ góc độ thị trường, trong khi bên "cầu" (người học) vẫn còn rất lớn; bên "cung" (cơ sở GD ĐH) vẫn còn quá mỏng: thống kê cho thấy, hiện nay chỉ có khoảng $30 \%$ thanh niên ở độ tuổi 18-22 ở nước ta là sinh viên đại học. Dư địa cho GD ĐH nói chung và GD ĐH tư thục nói riêng thực tế vẫn còn rất lớn.

Thế nhưng, sự phát triển ĐH TT sẽ không chỉ và không thể dừng lại ở chỗ là nơi tiếp nhận SV trượt ĐH công như thời gian trước. Tỷ lệ $26 \%$ học sinh THPT không đăng ký xét tuyển đại học năm học 2016-2017 chứng tỏ việc đào tạo của các trường đại học hiện nay nói chung, và ĐH TT nói riêng chưa đáp ứng được nhu cầu đào tạo để đáp ứng công việc thực tế, khiến học sinh phải lựa chọn các giải pháp thay thế khác như học nghề để có thể bắt tay vào lao động luôn. Việc xây dựng tốt các mô hình ĐH TT nhằm tập trung giải quyết được những nhu cầu cụ thể của từng ngành sản xuất sẽ mở rộng thị phần cho các trường ĐH TT, hướng tới những học sinh chưa từng nghĩ rằng mình sẽ có cơ hội học đại học. Thêm vào đó, sự xâm nhập của các trường quốc tế cũng là một tín hiệu khẳng định tiềm năng tăng trưởng của thị trường trong tương lai.

\footnotetext{
${ }^{3}$ Chapman, D., \& Chien, C. L. (2014). Higher Education in Asia: Expanding Out, Expanding Up. Montreal: UNESCO Institute for Statistics.
}

${ }^{4}$ MOET (2017). Higher Education Statistics 2016-2017. 